\title{
Ensino de desenho com uso de elementos da linguagem visual voltado à educação ambiental para surdos ${ }^{1}$
}

\section{Teaching drawing with the use of visual language elements aimed at environmental education for the deaf}

${ }^{1}$ Versão expandida do artigo selecionado nos Anais do Graphica 2019

\begin{abstract}
Alix Ribeiro da Silva
Mestre em Engenharia e Gestão do Conhecimento Doutorando no Programa de Pós-Graduação em Engenharia e Gestão do Conhecimento - Universidade Federal de Santa Catarina UFSC

Professor de Informática Educativa em regime ACT, no Estado de Santa Catarina, Biguaçu - Brasil alixribeiro@gmail.com
\end{abstract}

\section{Vania Ribas Ulbricht}

Mestre e doutora em Engenharia de Produção Docente do Departamento de Gestão do Conhecimento, no PPGEGC - UFSC,

Florianópolis, Brasil vrulbricht@gmail.com

\section{RESUMO:}

Este trabalho é um recorte de uma pesquisa de mestrado que objetivou desenvolver a partir do ensino de desenho com uso de elementos da linguagem visual, uma comunicação alternativa sobre Educação Ambiental para pessoas surdas. Na metodologia da pesquisa fez-se um estudo de caso realizado com seis alunos surdos pertencentes ao Atendimento Educacional Especializado da Escola de Educação Básica Nossa Senhora da Conceição, município de São José - Santa Catarina. 0 tema Educação Ambiental foi trabalho com os alunos por meio de diversas atividades didáticas, onde foram levantadas palavras-chave que foram usadas nas atividades de desenho. Para criação dos desenhos, trabalhou-se com elementos da linguagem visual (forma, linha, ponto e cor) por meio de atividades de coordenação motora. Conclui-se que, para os surdos o desenho pictográfico é uma forma de comunicação visual acessível que os auxilia a ter uma vida com autonomia.

Palavras-chave: desenho; linguagem visual; pessoas surdas; comunicação visual.

\section{ABSTRACT:}

This work is a cut of a master's research that aimed to develop from the teaching of drawing using elements of visual language, an alternative communication on Environmental Education for deaf people. In the methodology of the research, a case study was carried out with six deaf students belonging to the Specialized Educational Attendance of the School of Basic Education Nossa Senhora da Conceição, municipality of São José - Santa Catarina. The theme Environmental Education was work with students through various didactic activities, where keywords were raised that were used in drawing activities. To create the drawings, we worked with visual language elements (shape, line, point and color) through motor coordination activities. It is concluded that for the deaf the pictographic design is a form of accessible visual communication that helps them to have a life with autonomy.

Keywords: drawing; visual language; deaf people; visual communication. 


\section{INTRODUÇÃO}

Ribas (2018) aponta que, segundo dados da Organização Mundial da Saúde (OMS) e do Instituto Brasileiro de Geografia e Estatística (IBGE) referentes ao ano de 2010, 360 milhões de pessoas se autodeclararam deficientes auditivas no mundo. No Brasil, os dados indicaram 1.798 .967 pessoas com deficiência auditiva e destes, 344.206 se declararam surdas.

A partir dos dados, observa-se um alto número de pessoas surdas que necessitam de Tecnologias Assistivas e de novas formas didáticas que os auxiliem ter acesso à informação e ao conhecimento, e, assim, possibilite que os mesmos vivam com autonomia em uma sociedade que por tempos os discriminou e marginalizou-os, colocando-os fora dos interesses sociais (político, educacional, comunicacional, informacional, etc.).

Para o ensino de desenho com os alunos surdos, trabalhou-se com elementos da linguagem visual. Desta forma os alunos perceberam a facilidade em desenvolver e compreender desenhos simples com uso de elementos básicos da comunicação visual (ponto, linha, forma e cor), apresentados por Dondis (2015).

A imagem sendo tratada como linguagem e cheia de significados aos olhos de quem a interpreta, deve ser acessível a todos, assim, sendo importante a alfabetização visual. Para Couto (2000), a alfabetização visual contribui com habilidades e conhecimentos ao criador de imagens, que em primeiro lugar deve "conhecer mesmo que intuitivamente, um "vocabulário" ou uma "gramática", antes de elaborá-la; segundo, porque a imagem possui a capacidade de referência, a representatividade, capacidade esta que é também propriedade dos signos linguísticos" (COUTO, 2000, p. 14).

Neste trabalho, buscou-se relacionar o desenho com conhecimentos de Educação Ambiental, para que assim, o aluno surdo pudesse aprender conhecimentos ambientais de forma lúdica com uso de desenho. Para tanto, foi realizado diversas atividades sobre Educação Ambiental com os seis alunos surdos, para que estes pudessem ter acesso a possíveis conhecimentos e depois pudessem reforçar com a prática do desenho.

Apresenta-se neste trabalho um recorte de uma dissertação de mestrado, onde, foi feito um estudo de caso, que, segundo Yin (2001), além de utilizar técnicas de pesquisas históricas, permite agregar diversas fontes de evidências, como interrogações dos acontecimentos estudados e entrevistas, realizada com alunos surdos.

A pesquisa foi realizada por meio da técnica de pesquisa-ação durante cinco meses, com seis alunos surdos frequentastes da sala de Atendimento Educacional Especializado (AEE), na Escola Nossa Senhora da Conceição, no Município de São José Santa Catarina.

Justifica-se o ensino de desenho para alunos surdos, pelo benefício que esses terão na leitura de imagens visuais encontradas nos diversos ambientes da sociedade. Neste estudo, trabalhou-se com desenhos que envolvem Educação Ambiental, um tema de interesse social para preservação e conservação do ambiente natural. Apesar da relevância ambiental, o tema é de pouco acesso às pessoas surdas, outra justificativa que fundamenta este trabalho. 


\section{REVISÃO BIBLIOGRÁFICA}

\subsection{Um breve relato sobre o público alvo: as pessoas surdas}

Pensar sobre a surdez requer penetrar "no mundo dos surdos" e "ouvir" as mãos que, com alguns movimentos, nos dizem o que fazer para tornar possível o contato entre os mundos envolvidos, requer conhecer a "língua de sinais". Permita-se "ouvir" essas mãos, pois somente assim será possível mostrar aos surdos como eles podem "ouvir" O silêncio da palavra escrita (QUADROS, 1997, p. 119 apud Stumpf, 2005, p 43).

Segundo a Lei no 9.394/96 que propõe as diretrizes e bases da Educação Nacional, em seu Art. $2^{\circ}$, coloca que a educação é dever da família e do Estado, tendo como finalidade o pleno desenvolvimento do educando, seu preparo para o exercício da cidadania e sua qualificação para o trabalho. 0 ensino visa garantir igualdade de condições, liberdade de ensinar e aprender, qualidade no ensino, respeito às diferenças e atendimento educacional especializado às pessoas com deficiência, transtornos globais do desenvolvimento e altas habilidades ou superdotação.

São consideradas pessoas com deficiências aquelas "que têm impedimentos de longo prazo, de natureza física, mental ou sensorial que, em interação com diversas barreiras, podem ter restringida sua participação plena e efetiva na escola e na sociedade" (BRASIL, 2008 apud BRUNO; COELHO, 2016, p. 685). A inclusão escolar de pessoas com deficiência nas classes de ensino regular existe, e não pode negar-se. Porém, voltando-se ao surdo, essa inclusão nem sempre existiu, e atualmente é encarada com vários problemas que afetam a vida, o aprendizado e a socialização das pessoas surdas, na escola e na sociedade em geral.

Sabe-se que no passado, as atividades eram focadas na agricultura ou na produção industrial, sendo as pessoas com deficiência consideradas incapazes de realizar essas tarefas, além de serem consideradas um inconveniente para a sociedade, sendo por vezes escondidos ou presas e acorrentadas em porões ou abandonados à própria sorte, em alguns povos eram considerados amaldiçoados (SONZA, 2013). Com os surdos a situação não foi diferente, sendo esses excluídos do convívio em sociedade (SILVA, 2013).

Para Perlin e Strobel (2006, p. 5) “a história da educação de surdos não é uma história difícil de ser analisada e compreendida, ela evolui continuamente apesar de vários impactos marcantes". Contudo, cada momento da história afirma uma nova realidade de oportunidades para as pessoas surdas. Na educação, até a metade do século XVI, segundo Dias (2006) apud Merselian e Vitaliano (2009) os surdos não eram considerados educáveis, e por consequência, desnecessários para a coletividade.

No Brasil, a educação de surdos iniciou no ano de 1857 com a vinda do professor francês surdo Hernest Huet, formado pelo Instituto Nacional de Surdos e Mudos de Paris, cuja função era educar crianças surdas detentoras de bolsas de estudo cedidas pelo governo (GOLDFELD, 2002). Huet funda o Instituto Imperial de Surdos e Mudos, hoje nomeado de Instituto Nacional de Educação de Surdos (INES). O Instituto fazia uso da língua de sinais e do alfabeto datilológico, também conhecido como alfabeto manual (REILY, 2006). 
Entre as décadas de 80 e 90, surge o bilinguismo. Desde então o bilinguismo tem predominado como metodologia de ensino. Segundo Quadros (1997) apud Marinho (2007, p. 19) o bilinguismo é "uma proposta de ensino usada por escolas que propõem tornar acessível à criança duas línguas no contexto escolar".

A inclusão escolar de pessoas com deficiência nas classes de ensino regular existe, e não pode negar-se. Porém, voltando-se ao surdo, essa inclusão nem sempre existiu, e atualmente é encarada com vários problemas que afetam a vida, o aprendizado e a socialização das pessoas surdas, na escola e na sociedade em geral.

Bueno et al. (2014, p. 1) dizem que "os surdos têm sua própria cultura, um termo aplicado ao movimento social que mantém a surdez como uma diferença na experiência humana, em vez de uma deficiência". Ou seja, o termo deficiente não cabe aos surdos, pois, estes são surdos e possuem uma linguagem natural, a Língua de Sinais Brasileira (Libras), língua crucial para o desenvolvimento intelectual da comunidade surda.

\begin{abstract}
Grafia correta: Libras. Termo correto: língua de sinais brasileira. Trata-se de uma língua e não de uma linguagem. Segundo Capovilla (comunicação pessoal), "Língua de Sinais Brasileira é preferível a Língua Brasileira de Sinais por uma série imensa de razões". Uma das mais importantes é que Língua de Sinais é uma unidade, que se refere a uma modalidade linguística quiroarticulatória-visual e não oroarticulatória-auditiva. Assim, há Língua de Sinais Brasileira porque é a língua de sinais desenvolvida e empregada pela comunidade surda brasileira (SASSAKI, 2011, p. 6).
\end{abstract}

Para Gravel e O'Gara (2003), a maioria dos adultos surdos se auto identificam usuários da linguagem visual, ou seja, da Libras, um tipo particular de linguagem de caráter viso-espacial. Ainda segundo as autoras, alguns adultos surdos se consideram bilíngue, isto é, usam a língua de sinais para se comunicar dentro da comunidade surda e uma forma de comunicação oral para interações com indivíduos ouvintes. Porém, dentro da comunidade surda, o termo bilíngue é utilizado em referência aos surdos que fazem uso da Libras como primeira língua, e de uma segunda língua na modalidade escrita, no caso, a língua portuguesa (BUENO et al., 2014).

Outra forma de comunicação das pessoas surdas, é por meio do SignWriting. A escrita por meio de símbolos existe tanto nas línguas orais quanto nas de sinais (NOBRE, 2011). No caso do surdo, a representação da Libras se dá por meio da escrita de sinais (SignWriting), e não por meio do português na modalidade escrita, como muitos confundem (STUMPF, 2005). Segundo Stumpf (2005, p. 51-52) “o SignWriting pode registrar qualquer língua de sinais do mundo sem passar pela tradução da língua falada. Cada língua de sinais vai adaptar a sua própria ortografia".

SignWriting é o sistema de escrita de sinais utilizada pela comunidade surda, a Figura 1 mostra a escrita da palavra "surdo" em SignWriting. Inicialmente o sistema foi criado para escrever danças, despertando o interesse de pesquisadores de língua de sinais dinamarquesa que buscavam uma forma de escrever sinais (STUMPF, 2005; WANDERLEY, 2012). 
Figura 1: Escrita de surdo em SignWriting.
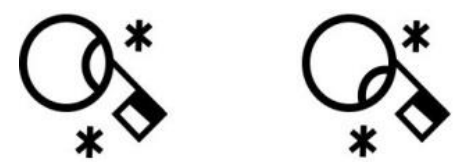

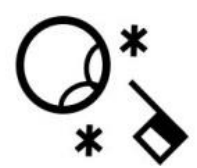

Fonte: Autores.
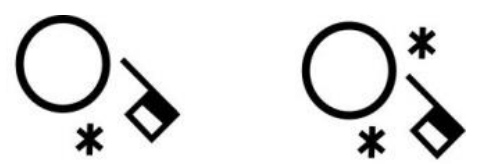

\subsection{Educação ambiental}

Educação Ambiental é um direito sancionado por meio da Lei 9.795/99 que institui a Política Nacional de Educação Ambiental e outras providências. Pela lei, entendese por Educação Ambiental as metodologias pelas quais o "indivíduo e a coletividade constroem valores sociais, conhecimentos, habilidades, atitudes e competências voltadas para a conservação do meio ambiente, bem de uso comum do povo, essencial à sadia qualidade de vida e sua sustentabilidade" (BRASIL, 1999).

Educação Ambiental é um tema a se trabalhar de forma interdisciplinar com os vários grupos que formam nossa sociedade, e, assim fazer valer a Constituição Federal que estabelece no Capítulo VI (do meio ambiente), artigo 225, no inciso VI, a necessidade de "promover à Educação Ambiental em todos os níveis de ensino e a conscientização pública para a preservação do meio ambiente" (BRASIL, 1988).

\subsection{Linguagem visual}

Para Piekas (2017), o campo da linguagem visual engloba conceitos e envolve um conjunto de signos que são fundamentais na comunicação entre os seres humanos e a representação no mundo por meio da imagem. "A linguagem visual é um fenômeno de cultura que se estrutura como imagem e se constitui como prática significante, isto é, prática de produção de sentido" (COUTO, 2000, p. 13).

A partir do pensamento de Couto (2000), de que a linguagem visual é um fenômeno cultural estruturado na imagem, se faz necessário um processo de alfabetização visual, pois como diz Piekas (2017, p. 28), “a imagem é geralmente apreciada de forma global, entretanto, as partes da imagem e a maneira como se articulam entre si merecem ser observadas e analisadas, ressaltando a importância da alfabetização visual".

A leitura da imagem visual não é imediata e depende da aprendizagem de sua linguagem. 0 que os autores Costa, Albuquerque e Carneiro-Leão (2017) chamam de letramento visual.

\subsubsection{Elementos básicos da linguagem visual}

Neste trabalho utilizou-se de quatro elementos básicos, sendo: ponto, linha, forma e cor.

Segundo Dondis (2015, p. 53) o ponto é considerado "a unidade de comunicação visual mais simples", entretanto, como diz Piekas (2017, p. 33) "mesmo sendo uma unidade mínima, ele atrai o olhar para o espaço em que está inserido". 
Quando qualquer material líquido é revertido sobre uma superfície, assume uma forma arredondada, mesmo que esta não simule um ponto perfeito. Quando fazemos uma marca, seja com tinta, com uma substância dura ou com um bastão, pensamos nesse elemento visual como um ponto de referência ou um indicador de espaço. Qualquer ponto tem grande poder de atração visual sobre o olho, exista ele naturalmente ou tenha sido colocado pelo homem em resposta a um objeto qualquer (DONDIS, 2015, p. 53).

Figura 2: ponto de referência no espaço.
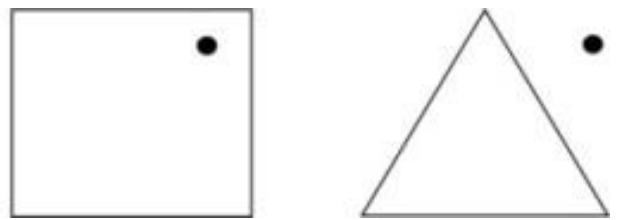

Fonte: Dondis (2015, p. 53).

Para Dondis (2015), dois pontos são utilizados como forma métrica para medir um dado espaço no ambiente, sendo empregados em qualquer projeto visual, haja vista que o ponto tem grande relevância na composição de um projeto visual quando usado como instrumento de referência para alguma marcação; ou quando vários pontos, juntos ou espaçados, preenchem a área possibilitando variações de tonalidades; ou quando, alinhados, podem sugerir linhas e figuras (DONDIS, 2015).

Dondis (2015) diz que o uso do ponto em um projeto visual depende da complexidade das medidas projetadas para a execução do projeto, quanto maior o projeto, mais pontos serão utilizados. À medida que se observa os pontos, estes passam a se ligar, sendo capazes de dirigir o olhar de quem observa. "Em grande número e justapostos, os pontos criam a ilusão de tom ou de cor" (DONDIS, 2015, p. 54).

Figura 3: Criação de tom com uso de pontos.

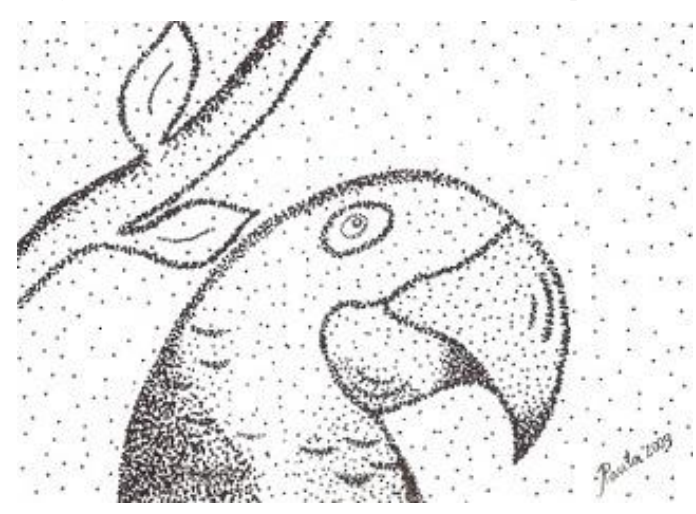

Fonte: Google imagens.

Na formação de uma imagem o ponto é considerado um elemento fundamental e conceitual. Wong (2001, p. 42) diz que na imagem o ponto "indica posição. Não tem comprimento nem largura. Não ocupa nenhuma área ou espaço. É o início e fim de uma linha e está onde duas linhas se encontram ou se cruzam".

0 elemento visual linha é considerado por Dondis (2015, p. 55) "como um ponto em movimento ou como a história do movimento de um ponto". Já Wong (2001, p. 43) caracteriza a linha por seu comprimento, sendo conceitual e visível (quando se expõe a 
linha no papel, Figura 5). Piekas (2017) apresenta a linha sobre três aspectos a partir das ideias de Massironi (1982), sendo a "linha-objeto, linha-contorno e linha-traço".

Dessa maneira, a linha-objeto pode ser entendida como um sinal gráfico aberto que caracteriza um objeto (como exemplo, desenho do tipo "homem palito"). Já a linhacontorno é caracterizada por um sinal gráfico fechado, a exemplo do desenho de um quadrado ou da fachada esquemática de uma casa, e a linha enquanto traço é definida como "textura", sendo assim denominada quando esse sinal gráfico se repete de maneira regular (PIEKAS, 2017, p. 33).

Wong (2001, p. 42) considera que "uma linha tem comprimento, mas não tem largura. Tem posição e direção. É limitada por pontos. Forma a borda de um plano". Dondis (2015) coloca que a linha é, um composto de pontos, que por estarem tão unidos, fica impossível identificar de forma individual cada ponto, assim, dando uma sensação de direção. "Quando fazemos uma marca contínua, ou uma linha, nosso procedimento se resume a colocar um marcador de pontos sobre uma superfície e movê-lo segundo uma determinada trajetória, de tal forma que as marcas assim formadas se convertam em registro" (DONDIS, 2015, p. 33).

A linha possui uma grande energia no campo das artes visuais. Assim, pode-se dizer que a linha está sempre em movimento, nunca sendo estática. A linha é considerada o elemento fundamental de pré-visualização de forma linear e fluida, onde, o desenhista pode projetar mentalmente e expor de forma palpável o esboço de uma obra não consumada, contribuindo para o processo de visualização (DONDIS, 2015).

"Apesar de sua flexibilidade e liberdade, a linha não é vaga: é decisiva, tem propósito e direção, vai para algum lugar, faz algo de definitivo" (DONDIS, 2015, p. 56). A linha é considerada um elemento fundamental na construção de projetos, em especial no Design e na Arquitetura. A linha pode ser usada em projetos com flexibilidade e experimental (Figura 5) ou com precisão e medidas rigorosas (Figura 4).

Figura 4: Pictograma de Jabuti.

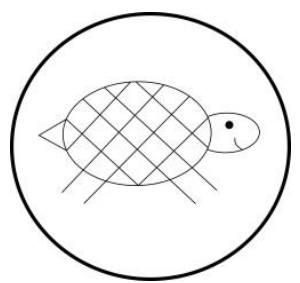

Fonte: Duarte e Piekas (2013, p. 143)
Figura 5: Desenho baseado no Pictograma Jabuti.

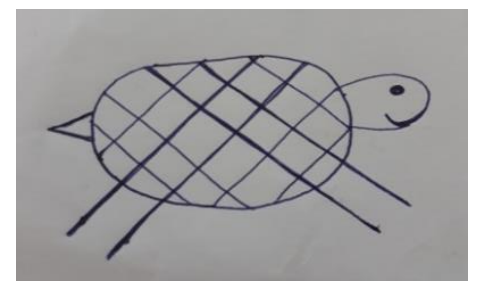

Fonte: Autores, baseado em Duarte e Piekas

(2013)

A linha se apresenta de várias formas (Figura 6). Nesse sentido, Dondis (2015, p. 57) diz que a linha "pode ser muito imprecisa e indisciplinada [...]. Pode ser muito delicada e ondulada ou nítida e grosseira [...]. Pode ser hesitante, indecisa e inquiridora, quando é simplesmente uma exploração visual [...]. Pode ser ainda tão pessoal quanto um manuscrito em forma de rabisco nervoso". 
Figura 6: Formas da linha em movimento.

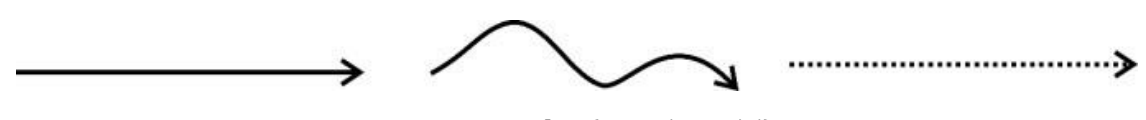

Fonte: Dondis (2015, p. 55).

Outro elemento é a forma, onde segundo Dondis (2015) é o resultado daquilo que a linha descreve e apresenta três formas básicas: o círculo, o quadrado e o triângulo (Figura 7). Cada forma tem sua característica própria. "Cada uma se atribui uma grande quantidade de significados, alguns por associação, outros por vinculação arbitrária, e outros, ainda, através de nossas próprias percepções psicológicas e fisiológicas" (DONDIS, 2015, p. 57-58).

Figura 7: Formas Básicas.

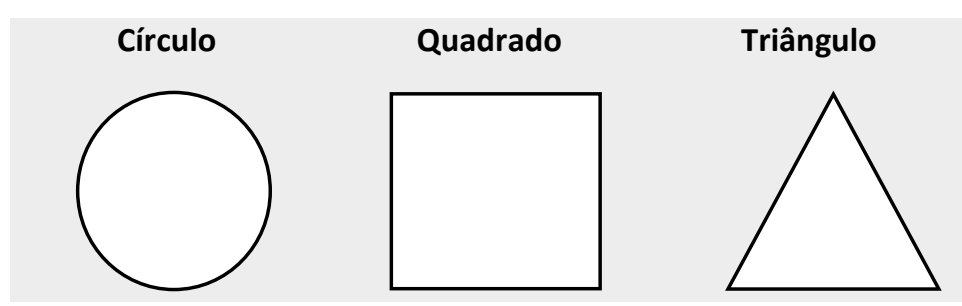

Fonte: Dondis (2015, p. 57).

Segundo os estudos de Bueno (2014) e de Dondis (2015), às formas possuem significados, sendo atribuído ao círculo o sentido de infinitude, calidez, proteção; ao quadrado o sentido de enfado, honestidade, retidão e esmero; e ao triângulo o sentido de ação, conflito, tensão. "Todas as formas básicas são figuras planas e simples, fundamentais, que podem ser facilmente descritas e construídas, tanto visual quanto verbalmente" (DONDIS, 2015, p. 58).

Para Dondis (2015) a combinação e a variação infinita das três formas básicas (círculo, quadrado e triângulo), deriva-se as demais formas físicas da natureza e da imaginação humana, conforme a Figura 8.

Figura 8: Formas básicas.

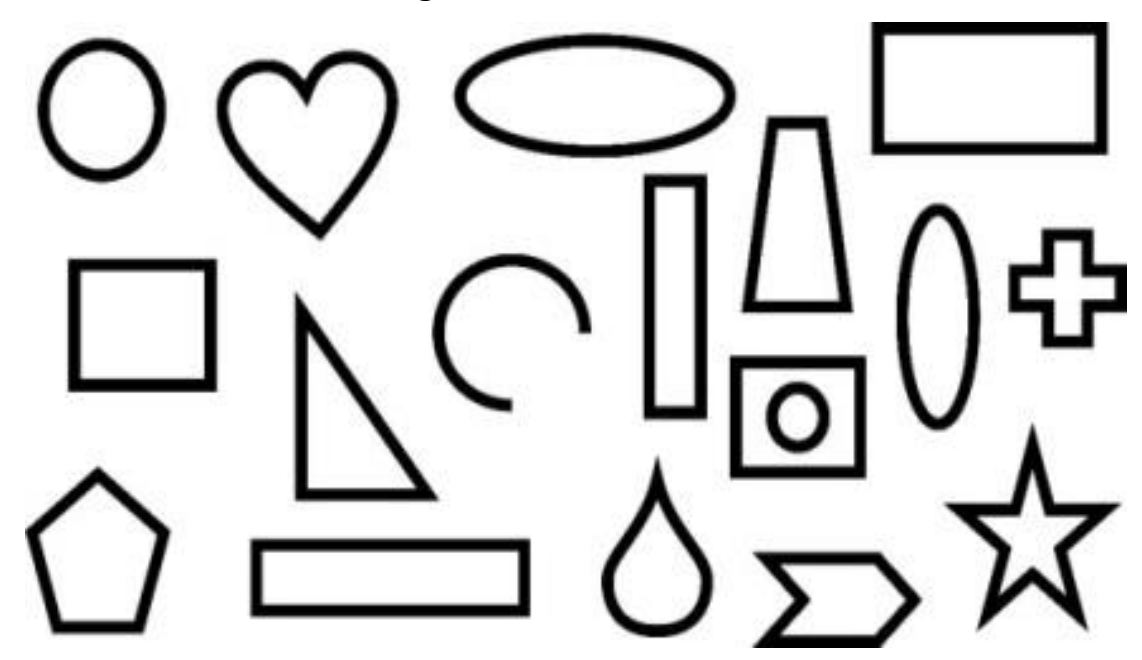

Fonte: Dondis (2015, p. 59). 
A cor é outro elemento da linguagem visual com grande relevância para a comunicação visual, pois, está impregnada de informações, dando significados ao universo colorido. "Enquanto o tom está associado à questão de sobrevivência, sendo, portanto, essencial para o organismo humano, a cor tem maiores afinidades com a emoção" (DONDIS, 2015, p. 64).

Dondis (2015), diz que a cor é um elemento visual que apresenta um grande valor para os comunicadores visuais, haja vista que a cor carrega informação, que dão significados associativos ao meio ambiente. 0 verde está ligado à cor das árvores; o azul, ligado ao céu e ao mar; o amarelo, ligado ao sol; o marrom, ligado a terra; o vermelho, ligado ao amor, ou a sangue, e etc. "Cada uma das cores também tem inúmeros significados associativos e simbólicos. Assim, a cor oferece um vocabulário enorme e de grande utilidade para o alfabetismo visual" (DONDIS, 2015, p. 64).

\begin{abstract}
Existem muitas teorias da cor. A cor, tanto da luz quanto do pigmento, tem um comportamento único, mas nosso conhecimento da cor na comunicação visual vai muito pouco além da coleta de observações de nossas reações a ela. Não há um sistema unificado e definitivo de como se relacionam os matizes (DONDIS, 2015, p. 65).
\end{abstract}

Dondis (2015) diz que são três as dimensões da cor que podem ser definidas e medidas. A primeira dimensão é a cor matiz ou croma. Nesta dimensão são apresentadas características individuais, existindo um número superior a cem, e cada grupo ou categoria de cores compartilham efeitos comuns. Para Dondis (2015), existem três matizes primários ou elementares, sendo a cor amarela, a cor vermelha e a cor azul.

Cada uma das cores consideradas por Dondis (2015) como primárias ou elementares, representam qualidades fundamentais. A cor amarela é a que está mais próxima da luz e do calor; a cor vermelha é considerada a mais ativa e emocional; e a cor azul se caracteriza como passiva e suave. A cor amarela e a vermelha são cores que tem uma tendência de se expandir, enquanto o azul tende a se contrair.

\title{
3. EDUCAÇÃO AMBIENTAL E ENSINO DE DESENHO PARA SURDOS
}

Desenhar é uma habilidade humana que faz parte do desenvolvimento cognitivo do ser humano, ou como diz Cox (2010, p. 4), a arte de desenhar "é parte importante do desenvolvimento infantil". Há pessoas que desenham com facilidade, parte de um dom artístico; e outras que desenham com dificuldades, criando "rascunhos" com significados; contudo, as diferentes formas de se expressar, com facilidade ou não, é parte de uma habilidade que chamamos de desenho.

Araújo e Lacerda (2008, p. 431) consideram inicialmente o desenho como brincadeira, um processo autocontido de representação "em seguida, o ato completo pode ser usado como estratagema: o desenho transforma-se, passando de simples representação para um meio, e o intelecto adquire um instrumento novo e poderoso na forma da primeira escrita diferenciada". 
Figura 9: Desenho feito pela aluna A4 representando a Fauna e Flora.

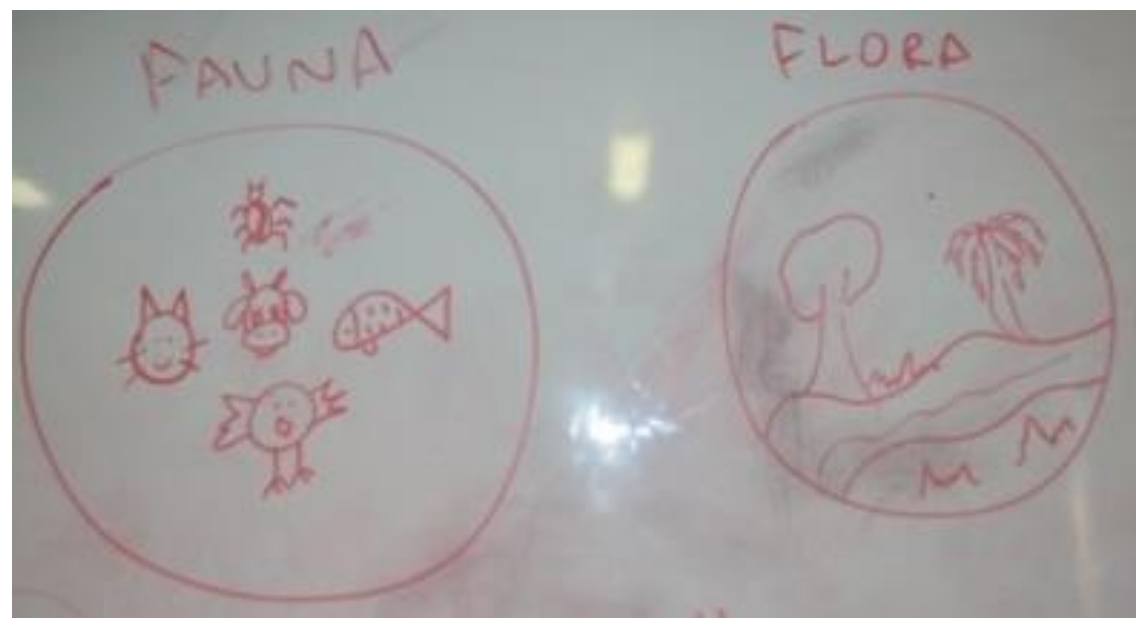

Fonte: Autores.

O desenho exposto na Figura 9 foi desenvolvido no quadro branco da sala de AEE, por uma aluna. Pode-se considerar o desenho criado pela aluna como uma arte que simboliza a fauna e a flora, ou seja, um desenho com significado real. No desenho da fauna, observam-se desenhos de espécies animais, como o peixe, animal aquático; o pássaro, animal voador; o gato, o boi e a aranha como animais terrestres, sendo o gato um animal doméstico domiciliar, o boi um animal doméstico de criação racional, e a aranha como animal silvestre. 0 desenho da flora é simbolizado por duas espécies de árvores.

A representação do desenho por meio de imagens, "em todas as suas formas, vem ocupando um papel cada vez mais importante na comunicação e interação social, e constitui-se como um recurso visual bastante utilizado pela criança" (ARAÚJO; LACERDA, 2010, p. 696). Para Cox (2010) a maioria das crianças mostram interesses e sentem prazer por desenhar, preocupando-se com a identificação dos objetos de seus desenhos.

Para Derdyk (2015, p. 24) “a criança é um ser em contínuo movimento. Este estado de eterna transformação física, perceptiva, psíquica, emocional e cognitiva promove na criança um espírito curioso, atento e experimental". 0 espírito de curiosidade, de atenção e de experiência da criança, juntamente do espírito artístico e por meio da imaginação, leva-os a expor por meio de desenhos a experiência de vida, guardando na memória e no "papel" parte de suas vidas.

Ao trabalhar o ensino de desenho com os surdos, abordando desenhos de EA, percebeu-se grande curiosidade a respeito do tema, levando-os a ter atenção em aprender (sobre Educação Ambiental e a desenhar), haja vista que, o conhecimento dos alunos era limitado a suas experiências de vida, como questões ligadas ao lixo e a animais, em especial os domésticos.

Trabalhando-se com o ensino de desenho, abordou-se a linguagem visual, iniciando primeiramente com linhas e formas, conforme Figura 10, para que os alunos pudessem ter familiaridade com o tema, e, assim iniciassem o processo de aprendizagem para criação de desenhos a partir de suas observações e entendimento do objeto sobre Educação 
Figura 10: Elementos da linguagem visual.

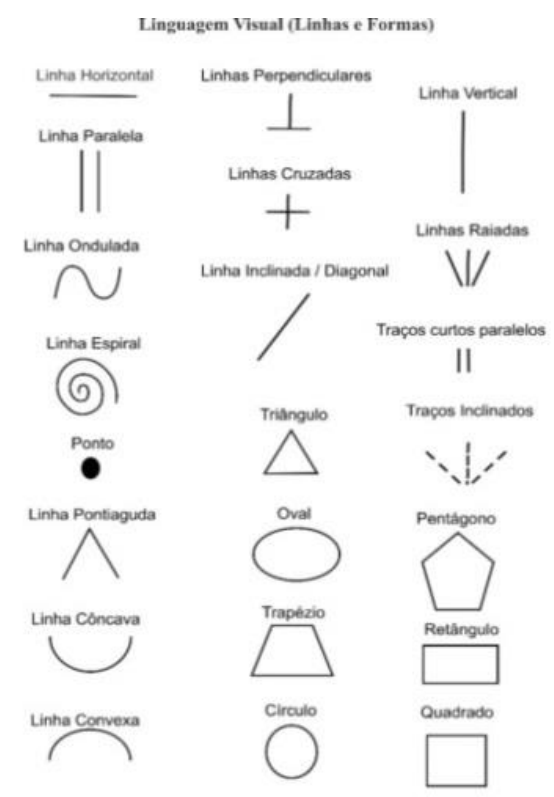

Fonte: Autores.

Após trabalhar-se com os alunos algumas formas e linhas da linguagem visual, solicitou-se que realizassem uma atividade para exercitar a coordenação motora, além de tamanho e espaço, como se observa na Figura 11. Na atividade, havia o nome do termo da linguagem visual em um pequeno quadro, e o aluno devia realizar o desenho, baseandose no que haviam aprendido sobre linhas e formas. Antes de fazer o desenho na folha da atividade, os alunos exercitaram em folhas de rascunhos.

Figura 11: Trabalho de coordenação motora.
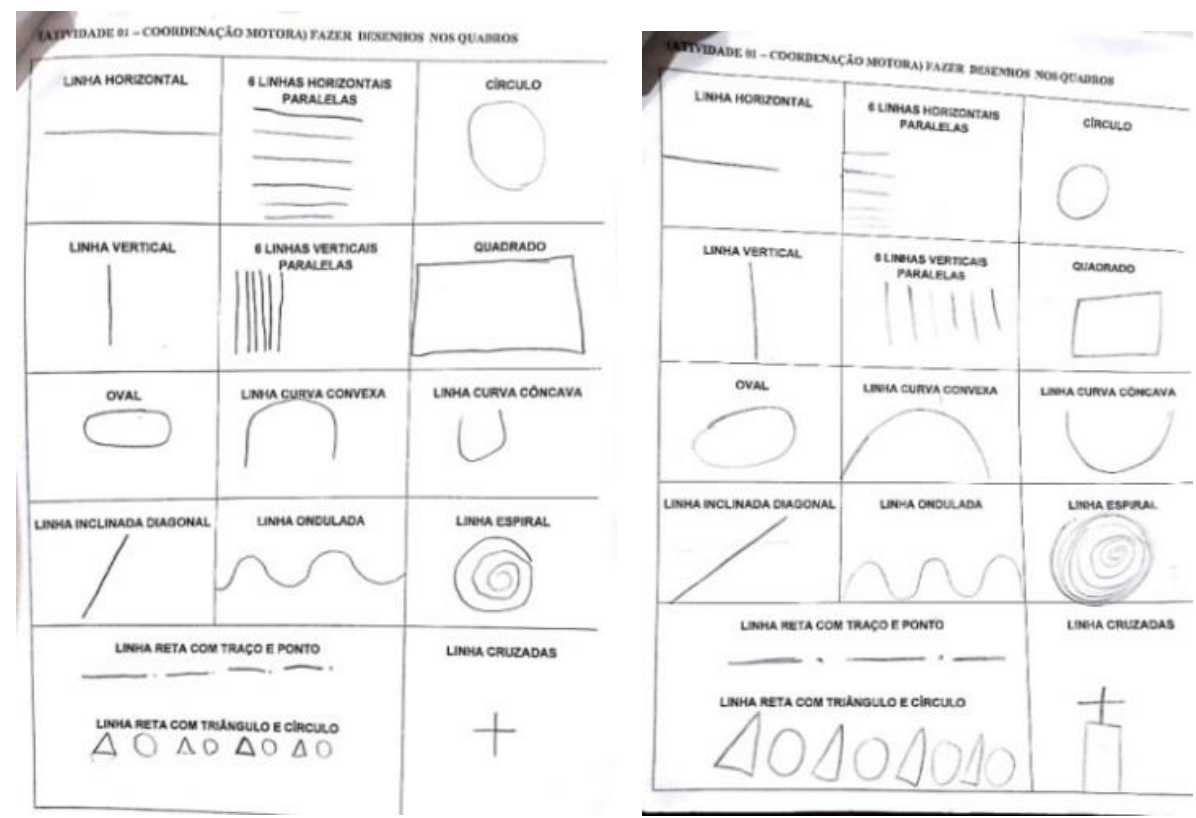

Fonte: Autores.

Na próxima atividade com os alunos, para o ensino de desenho, também teve como objetivo trabalhar a coordenação motora e a percepção por meio do raciocínio 
lógico do aluno ao observar uma imagem com um conjunto de pontos sem relação entre si. Na Figura 12, os alunos deveriam traçar uma linha passando uma única vez por cima de cada ponto, devendo ter um ponto inicial e um final.

Figura 12: Atividade de coordenação motora ligando pontos.
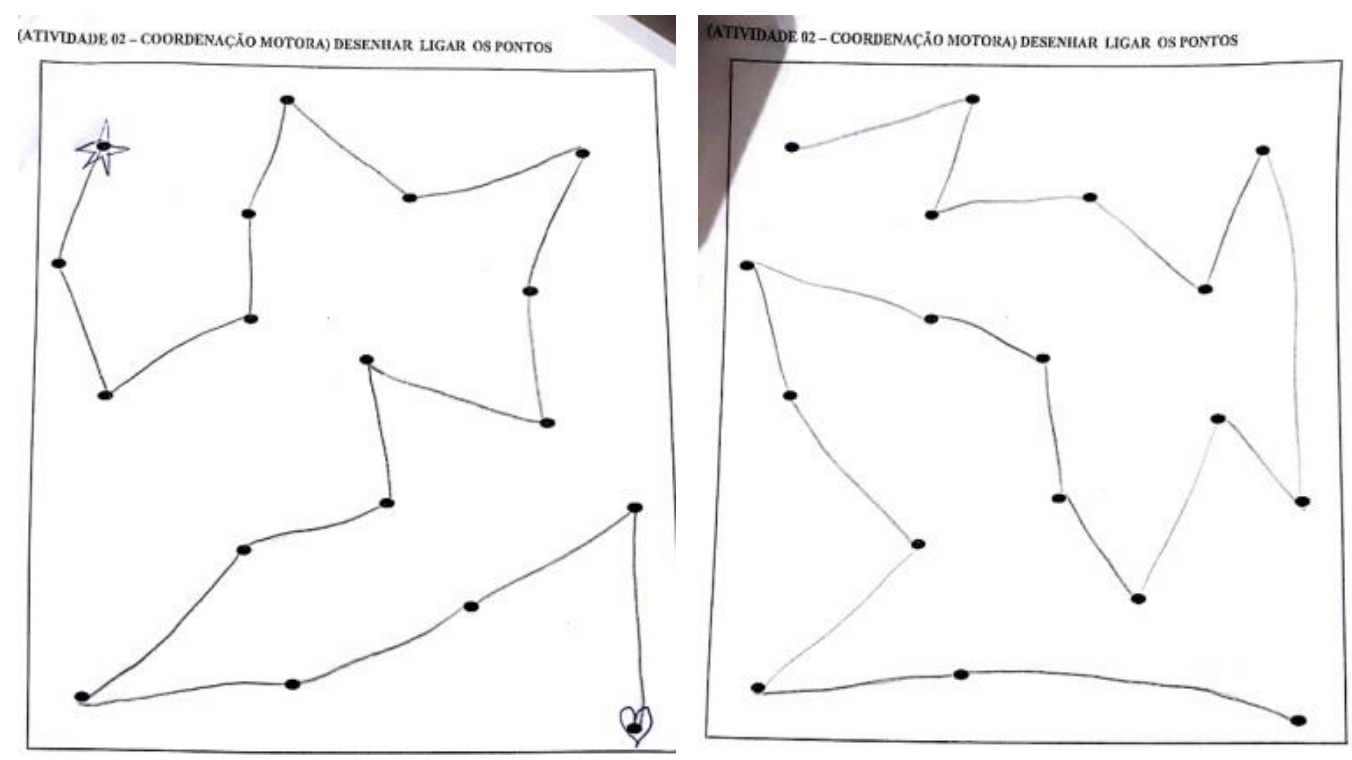

Fonte: Autores.

Outra atividade com o uso de pontos, porém, dessa vez os pontos apresentavam relação entre si, e que, se ligados corretamente formavam um desenho, sendo o desenho de um barco, de uma casa, de uma árvore e de um coração. A Figura 13 mostra a aluna A6 realizando a atividade.

Figura 13: Atividade com Aluna A6.

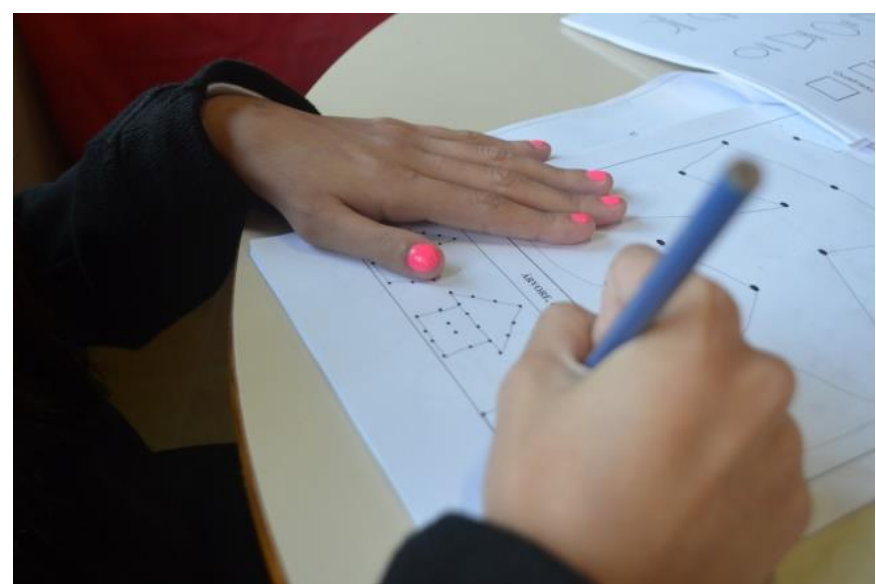

Fonte: Autores.

Nesta atividade, além da coordenação motora do aluno, destacou-se o uso de cor e a percepção visual do aluno surdo, onde quase todos os desenhos foram ligados corretamente, com exceção do desenho do aluno A5, da Figura 14, que, ao invés de perceber e desenhar um barco, observou e desenhou o que para ele era um sapato com salto alto. 
Figura 14: Atividade dois, coordenação motora, ligar os pontos.
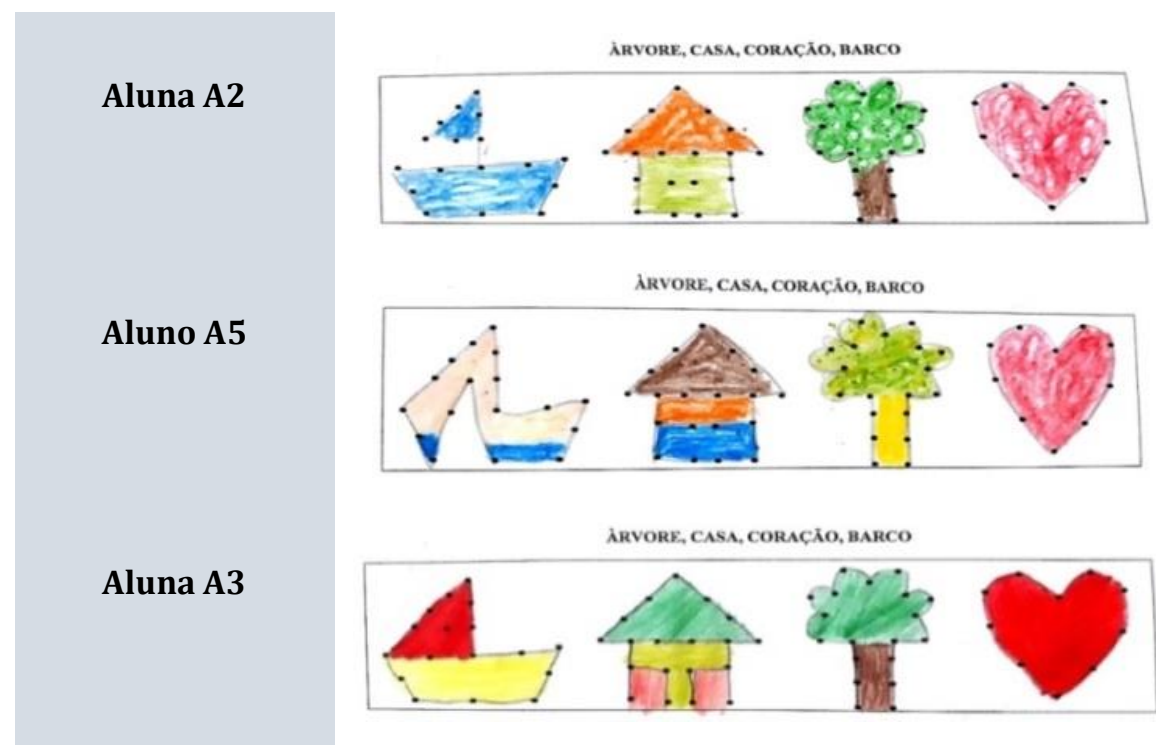

Fonte: Autores.

A atividade próxima foi para ter concepção do nível de capacidade em desenhar fazendo uso de elementos da linguagem visual. Na atividade foi pedido aos alunos que realizassem três desenhos, sendo um desenho de paisagem, um da escola e outro de uma floresta.

Figura 15: Atividade de desenho com os alunos.
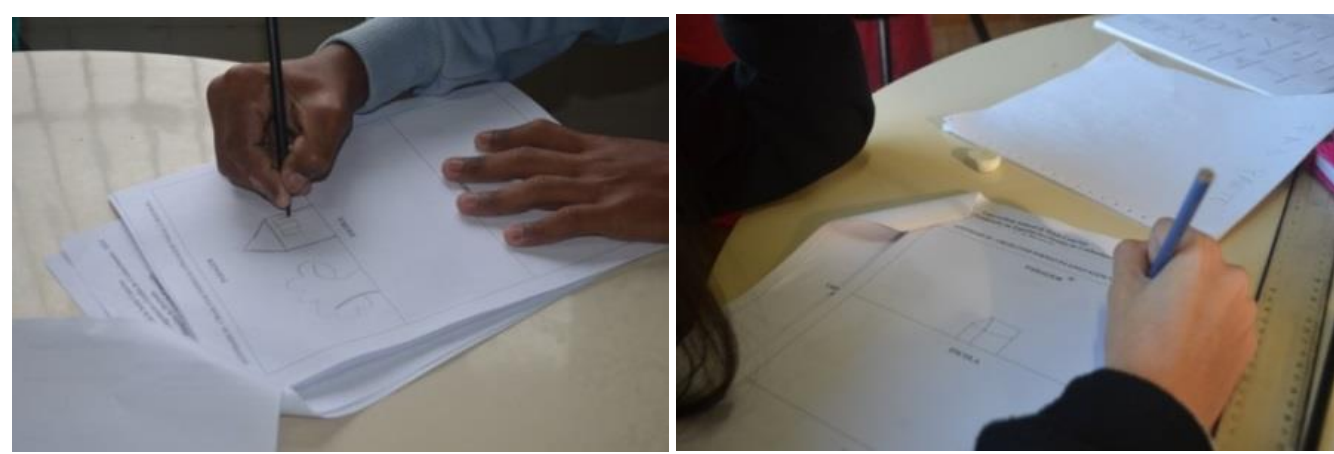

Fonte: Autores.

Para os alunos surdos da pesquisa, o desenho colorido pareceu ser mais fácil de visualizar e identificar seu significado, pois as cores demarcam o limite e separação das partes que compõem um desenho. Além de que, a cor os leva a associar a imagem a seu sentido. 
Figura 16: Atividade de desenho com uso de elementos da linguagem visual.
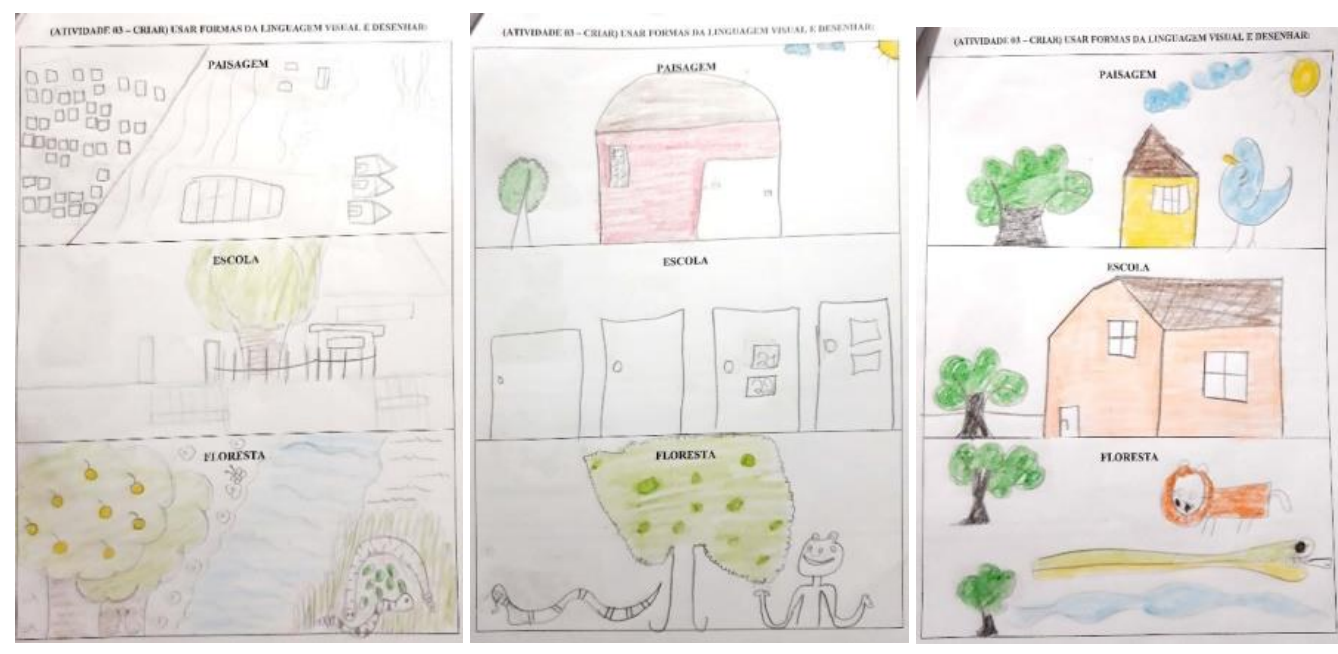

Fonte: Autores.

Os desenhos das figuras acima foram desenhados pelos alunos sem intervenção da equipe de pesquisa. Logo, os desenhos não levam ou não foram desenhados a partir dos elementos da linguagem visual, ainda que se percebam alguns elementos como formas, linhas e cores.

Outra atividade de ensino de desenho foi fazendo uso do esquema gráfico de pictogramas de animais, sendo ensinado aos alunos o passo a passo, visualizando cada elemento da linguagem visual até construção do desenho, conforme Figura 17 e 18.

A Figura 17 é o esquema de construção do animal veado a partir do uso dos elementos da linguagem visual, e a Figura 18 é de um peixe-boi. Na primeira coluna, observa-se a sequência para construção do desenho, por meio das linhas em negrito. A segunda coluna é os elementos da linguagem visual. A terceira coluna é o desenho base feito pelos alunos surdos, e o pictograma em preto e branco e o colorido. 0 pictograma colorido foi pedido pelos alunos surdos, pois, a cor facilita a visualização e identificação do elemento. 
Figura 17: Sequência de ELV para Pictograma de Veado.

Soquencia

Fonte: Autores.

Figura 18: Sequência de ELV para Pictograma de Peixe-Boi.

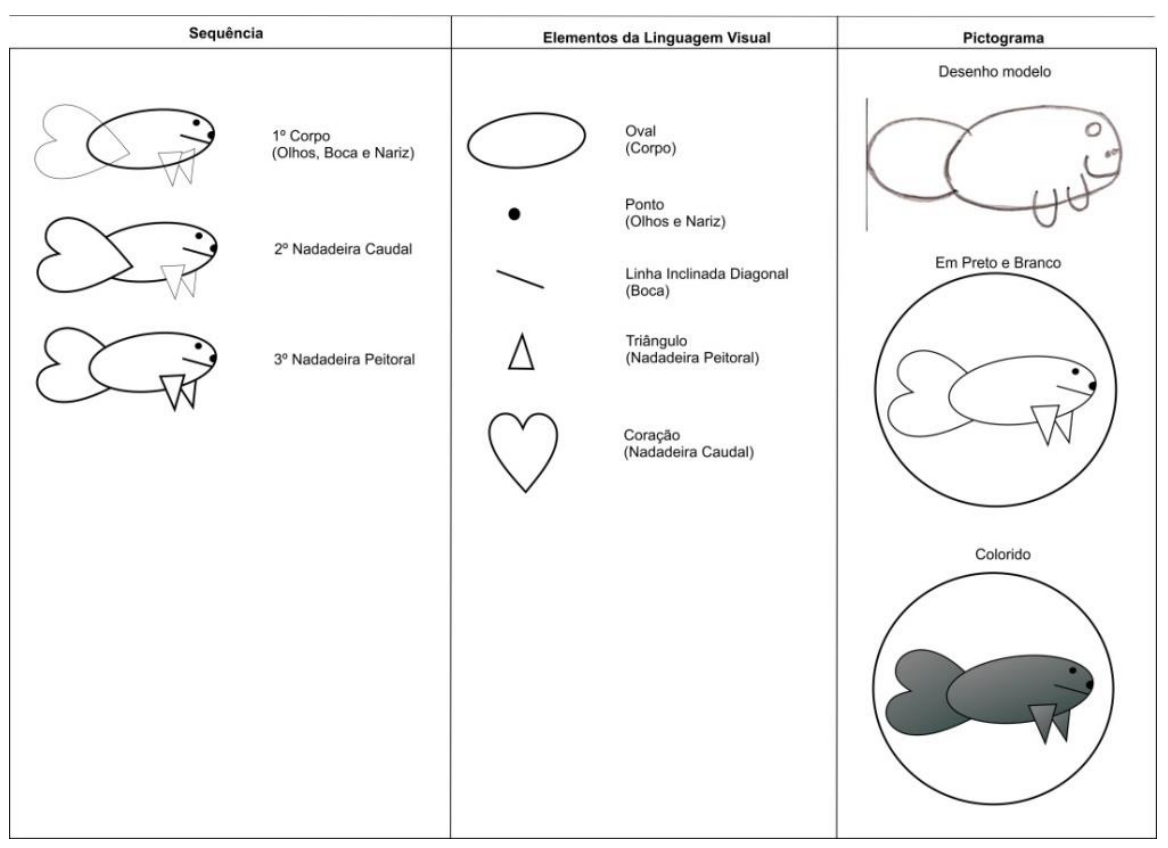

Fonte: Autores. 


\section{CONSIDERAÇÕES FINAIS}

Considerando as mudanças de estilos de vida e avanço das tecnologias, a comunicação visual com uso de desenhos se tornou algo casual, sendo de preferência de muitos usuários.

Trabalhar um determinado conhecimento fazendo uso da arte de desenhar, em especial com pessoas com deficiência que apresentam um determinado sentido do corpo comprometido, neste caso o surdo, com sentido da audição, é uma saída que possibilita o aprendizado desses de forma lúdica, uma forma de promover acessibilidade e assim promover autonomia por meio da comunicação visual.

A partir deste trabalho, foi possível adquirir indicativos do nível de conhecimento em Educação Ambiental dos alunos e contribuir com novos conhecimentos, tanto em caráter de ensino formal quanto não formal.

Apesar de o trabalho ter sido realizado com alunos surdos, é possível empregar a metodologia de ensino de desenho apresentado nesta pesquisa com outras pessoas com deficiência e para além de pessoas com deficiência, pois os desenhos apresentados foram feitos de forma simples, com uso de elementos básicos da linguagem visual, como forma, linha, ponto e cor.

Com a prática de ensino de desenho, buscou-se eliminar o máximo de detalhes que pudessem dificultar a comunicação visual do surdo, ou mesmo do ouvinte e qualquer pessoa que faça uso de comunicação visual.

Por fim, considera-se que este trabalho contribuiu com o processo de inclusão social a partir de atividades teóricas e práticas na escola; e de comunicação, por meio do ensino de desenho para auxiliar na comunicação visual, referentes à Educação Ambiental.

Ao fim da pesquisa, pode-se dizer que a escolha do tema Educação Ambiental foi de ampla relevância a ser trabalhada com os alunos surdos, visto que os conhecimentos ambientais desses alunos se mostraram reduzidos a conhecimentos do dia-a-dia.

\section{REFERÊNCIAS BIBLIOGRÁFICAS}

ARAÚJO, C. C. M.; LACERDA, C. B. F. Linguagem e desenho no desenvolvimento da criança surda: implicações histórico-culturais. Psicologia em estudo - Maringá, v. 15, n. 4, p. 695-703, 2010.

BRASIL. Lei no 9.795, que dispõe sobre a educação ambiental, institui a Política Nacional de Educação Ambiental e dá outras providências. Brasília: 1999. 1988.

Constituição da República: Capítulo XI do meio ambiente, art. 225 - Brasília,

BRUNO, M. M. G.; COELHO, L. L. Discourses and Practices in the Inclusion of Deaf Indians in Differentiated Indigenous Schools. Revista Educação e Realidade, vol.41. Porto Alegre - 2016. Disponível em: < http://www.scielo.br/scielo.php?pid=S217562362016000300681\&script=sci_arttext\&tlng=en>. Acesso em: 22 ago. 2019. 
BUENO, J.; ULBRICHT, V. R.; SPINILLO, G. C.; GARCÍA, L. S. Crianças surdas e ouvintes: um estudo comparativo sobre as preferências de cor, forma e estilo de desenho. Anais do 6th Information Design International Conference, vol. 1 num. 2, São Paulo, 2014.

COUTO, R. C. A Escolarização da linguagem visual: uma leitura dos documentos ao professor. Dissertação de Mestrado apresentado ao Programa de Pós-Graduação em Educação da UFMG, 2000.

COSTA, J. S; ALBUQUERQUE, T. C. C; CARNEIRO-LEÃO A. M. A. Letramento visual e formação de professores: habilidade de leitura de imagens para o ensino de conceitos biológicos. XI Encontro Nacional de Pesquisa em Educação em Ciências, Florianópolis - 2017.

COX, M. Desenho da Criança. 3ª Ed. - São Paulo: Martins Fontes, 2010.

DERDYK, E. Formas de pensar o desenho: desenvolvimento do grafismo infantil. 5a ed. - Porto Alegre, RS: Zouk, 2015.

DONDIS, D. A. Sintaxe da linguagem visual. 3ª ed. São Paulo: Martins Fontes, 2015.

DUARTE, M. L.; PIEKAS, M. I. Vocabulário pictográfico para a educação inclusiva. Parte 1 - Animais. Curitiba: Insight, 2013.

GOLDFELD, M. Linguagem e cognição numa perspectiva sociointeracionista. São Paulo: Plexus, 2002.

GRAVEL, J. S.; O'GARA, J. Communication options for children with hearing loss. Mental Retardation and Developmental Disabilities Research Reviews. Vol. 9, ed. 4, p. 243251, 2003.

MARINHO, M. L. 0 ensino da biologia: o intérprete e a geração de sinais. 2007. 144 f. Dissertação (Mestrado) - Curso de Letras, Departamento de Departamento de Linguística, Português e Línguas Clássicas, Universidade de Brasília, Brasília, 2007

MERSELIAN, K. T.; VITALIANO, C. R. Análise sobre a trajetória histórica da educação dos surdos. IX Congresso Nacional de Educação, PUC-PR. 2009.

PERLIN, G.; STROBEL, K. L. Fundamentos da Educação de Surdos. CCE - UFSC, Florianópolis, 2006.

PIEKAS, M. I. Elementos da linguagem visual e ensino de desenhos para crianças cegas. Tese de Doutorado. Florianópolis: UDESC, 2017.

REILY, L. Escola inclusiva: linguagem e mediação. São Paulo: Papirus, 2006.

RIBAS, A. C. Diretrizes para desenvolvimento de ícones digitais acessíveis ao público surdo. Tese de Doutorado apresentado ao Programa de Pós Graduação em Engenharia e Gestão do Conhecimento, 2018. 
SASSAKI, R. K. Terminologia sobre deficiência na era da inclusão. Versão atualizada, 2011. Disponível em: <http://www.ocuidador.com.br/imgs/utilidades/terminologia50aa23697289a.pdf>. Acesso em 13 out. 2019.

NOBRE, R. S. Processo de grafia da língua de sinais uma análise fono-morfológica da escrita em signwriting. Dissertação de Mestrado apresentado ao Programa de PósGraduação em linguística aplicada da UFSC - 2011.

SILVA, J. F. C. 0 ensino de física com as mãos: libras, bilinguismo e inclusão. 2013. 219 f. Dissertação (Mestrado) - Curso de Ciências, Universidade de São Paulo, São Paulo, 2013.

SONZA, A. P. Acessibilidade e tecnologia assistiva: pensando a inclusão sociodigital de pessoas com necessidades especiais. Bento Gonçalves: BBB, 2013, 368 p.

STUMPF, M. R. Aprendizagem de escrita de língua de sinais de pelo sistema signwriting: linguas de sinais no papel e no computador. Tese de Doutorado apresentada ao Programa de Pós-Graduação em Informática na Educação da UFRGS 2005.

WANDERLEY, D. C. Aspectos da leitura e escrita de sinais: estudos de caso com alunos surdos da educação básica e de universitários surdos e ouvintes. Dissertação de Mestrado apresentado ao Programa de Pós-Graduação em linguística aplicada da UFSC 2012.

WONG, Wucius. Princípios de forma e desenho. 2. Tiragem. São Paulo: Martins Fontes, 2001.

YIN, R. K. Estudo de caso: planejamento e métodos. 2.ed., Porto Alegre: Bookman, 2001.

\section{AGRADECIMENTOS}

Ao Programa de Pós-Graduação em Engenharia e Gestão do Conhecimento PPGEGC, bem como a Universidade Federal de Santa Catarina, e apoio da CAPES pela Bolsa de Pesquisa que auxiliou durante o desenvolvimento do estudo. Também, agradecemos a Secretaria Estadual de Educação de Santa Catarina, e a Escola de Educação Básica Nossa Senhora da Conceição, pela autorização de realização da pesquisa. 